\title{
DEVELOPMENT OF KBIM E-SUBMISSION PROTOTYPICAL SYSTEM FOR THE OPENBIM-BASED BUILDING PERMIT FRAMEWORK
}

\author{
Inhan $\mathrm{KIM}^{1}$, Jungsik $\mathrm{CHOI}^{2}$, Evelyn Ai Lin $\mathrm{TEO}^{3}$, Hongwei SUN ${ }^{1^{*}}$ \\ ${ }^{1}$ Department of Architecture, Kyung Hee University, Yongin, Republic of Korea \\ ${ }^{2}$ Major in Architecture IT Convergence Engineering, Division of Smart Convergence Engineering, \\ Hanyang University, Ansan, Republic of Korea \\ ${ }^{3}$ Department of Building, National University of Singapore, 4 Architecture Drive, 117566 Singapore, Singapore
}

Received 1 May 2020; accepted 8 October 2020

\begin{abstract}
With the popularization of Building Information Modeling (BIM) technology, increasing numbers of countries are attempting to introduce BIM into their national building permitting processes. There are also many BIM-related research initiatives worldwide. Likewise, the Korean government has joined this trend by improving its existing e-Submission system, SEUMTER, to provide for BIM-based e-submission and automated code compliance checking. Further, the Ministry of Land, Infrastructure, and Transport in Korea has funded the Korea BIM (KBIM) building e-Submission system project. The Industry Foundation Classes (IFC) data model is an openBIM approach that has been designated as an international standard through the International Organization for Standardization. It is not dependent on specific design tools and is suitable for public works applications. Hence, this study performed a comprehensive analysis of and developed a framework for a prototypical system for an e-Submission process based on the IFC data model. Four main modules were developed to perform code checking, submission, pre-checking, and automated rule-making. A real-world project was used to verify the feasibility and effectiveness of the proposed framework. This study could increase the adoption of BIMbased building e-Submission systems by sharing effective and successful processes.
\end{abstract}

Keywords: building information modeling (BIM), industry foundation classes (IFC), building e-Submission system, automated code compliance checking, building code, pre-checking.

\section{Introduction}

With the popularization of smart devices and the application of artificial intelligence and other automation technologies, numerous industries have leveraged these technical advances to innovate their business processes. The construction field is striving to improve productivity, innovation, and quality by applying openBIM (Choi et al., 2018). Many countries are becoming aware of the importance of BIM and are exploring its potential applications. However, there is a lack of unified standards for BIM processes, leading to BIM technology not being used effectively. Therefore, the government must play a guiding role to accelerate the adoption of BIM, and many countries have mandated the use of BIM in a stepwise manner and issued BIM-related policies. For example, since 2015 (Building and Construction Authority [BCA], 2015), Singapore has required that new buildings that are more than $5000 \mathrm{~m}^{2}$ be submitted as a BIM model, and, in Korea, BIM has been compulsory for all public sector projects since 2016 (Cheng \& Lu, 2015; Edirisinghe \& London, 2015). However, after such mandate, the submitted model has no significant effect on the permitting process, and many of the models are only used as a reference for checking designs, while the permitting approvals are still based on checking the $2 \mathrm{D}$ drawings. These issues of being unable to check the submitted 3D BIM model and the integration of the submitted BIM documents into the existing electronic submission system still persist. Therefore, the Korean government funded a project to create the KBIM building e-Submission system based on the openBIM approach to overcome these issues. The project is divided into two stages. In the first stage, which is described in this paper, the proposed prototypical system was tested in an environment that was similar to that of the existing architectural administration information system (SEUMTER).

${ }^{\star}$ Corresponding author. E-mail: hongwei@khu.ac.kr

Copyright $\odot 2020$ The Author(s). Published by Vilnius Gediminas Technical University

This is an Open Access article distributed under the terms of the Creative Commons Attribution License (http://creativecommons.org/licenses/by/4.0/), which permits unrestricted use, distribution, and reproduction in any medium, provided the original author and source are credited. 
The second stage will further expand the proposed system developed in the first stage, with plans for putting the system into practical use by the government afterwards. The primary aim of this paper is to introduce the framework of the prototypical KBIM e-Submission system and its key features. The extensive experience resulting from efforts of South Korea to implement this BIM-based e-Submission system could help to promote the advancement of BIM technology worldwide.

The structure of the paper is organized as follows. Section 1 provides a review of the literature and the status of current building e-submission processes in different countries to establish its advantages and limitations. An analysis of the primary issues influencing the e-submission process and the features of BIM models is provided in Section 2. Four modules are proposed, and the purpose of each is discussed. In Section 3, an overview of the prototypical openBIM-based KBIM building e-submission system is presented, introducing the function and role of each module in the process. In Section 4, the authors will validate the feasibility and effectiveness of the prototypical system in an actual project. Finally, the conclusion summarizes the framework proposed in this paper and proposes future research topics.

\section{Existing building e-Submission systems and automated code checking}

\subsection{Building e-Submission systems status in different countries}

The BIM-based e-Submission systems found in Singapore, Norway, the United Kingdom, and South Korea were reviewed, and Table 1 depicts the current status of the various e-Submission systems of these four countries.

\subsubsection{Singapore}

Singapore has an internet-based system, the Construction and Real Estate Network (CORENET), where industry professionals submit project-related files to regulatory authorities for approval. It has been implemented by the Singapore Building and Construction Authority since 1995 and consists of e-Submission, e-PlanCheck, and CORENET e-Info. E-PlanCheck is a checking system based on FORNAX, which was started initially a 2D-based review system; in September 1998, it transitioned to operate on industry foundation classes (IFC) building model data (Eastman et al., 2009; Kim et al., 2018a). However, in Singapore's 'Code of Practice for Building Information Modelling (BIM) e-Submission', for the general requirements for the early 2000s, acceptable file format has mandated to be in native file format and lightweight format (BCA, 2016a). In 2016, the Singapore Building and Construction Authority invited tenders to develop rule-based code compliance checking for BIM models to fully harness the capability of BIM and improve overall construction productivity, under the iGrant innovation project (BCA, 2016b). Currently, Singapore has an active tender for CORENET-X project as a post iGrant innovation project (GeBIZ, 2020).

\subsubsection{Norway}

The ByggSøk system is a public system that facilitates the electronic processing of zoning and building matters in Norway and comprises three modules: an information system, a system for submitting building applications, and a system for zoning proposals (Choi \& Kim, 2015). The first version was launched in July 2013 (Hjelseth, 2015). Statsbygg is the Norwegian government's key advisor in construction and property matters and serves as their

Table 1. Current status of e-Submission systems in different countries

\begin{tabular}{|c|c|c|c|c|}
\hline & Singapore & Norway & United Kingdom & South Korea \\
\hline $\begin{array}{l}\text { Establishing } \\
\text { e-Submission } \\
\text { platform }\end{array}$ & $\begin{array}{l}\text { Yes, CORENET } \\
(1995-)\end{array}$ & $\begin{array}{l}\text { Yes, ByggSøk } \\
(2003-)\end{array}$ & $\begin{array}{l}\text { Yes, Planning Portal } \\
(2002-)\end{array}$ & $\begin{array}{l}\text { Yes, SEUMTER } \\
(2009-)\end{array}$ \\
\hline Lead authority & $\begin{array}{l}\text { Building \& Construction } \\
\text { Authority }\end{array}$ & $\begin{array}{l}\text { Norwegian Building } \\
\text { Authority }\end{array}$ & UK government & $\begin{array}{l}\text { Ministry of Land } \\
\text { Infrastructure and Transport } \\
\text { in Korea (MOLIT) }\end{array}$ \\
\hline $\begin{array}{l}\text { Mandatory BIM } \\
\text { policy }\end{array}$ & $\begin{array}{l}\text { Required for new buildings } \\
\text { that are more than } 5000 \mathrm{~m}^{2} \\
\text { since } 2015\end{array}$ & $\begin{array}{l}\text { Mandated on all } \\
\text { public sector projects } \\
\text { since } 2010\end{array}$ & $\begin{array}{l}\text { Model-based BIM (level 2) } \\
\text { mandated on all public } \\
\text { sector projects in } 2016\end{array}$ & $\begin{array}{l}\text { Mandated by Public } \\
\text { Procurement Service since } \\
2016\end{array}$ \\
\hline $\begin{array}{l}\text { Required data } \\
\text { format }\end{array}$ & $\begin{array}{l}\text { Native File Format } \\
\text { and } \\
\text { Lightweight File Format }\end{array}$ & $\begin{array}{l}\text { IFC, Native } \\
\text { (Statsbygg, } \\
\text { 2013) }\end{array}$ & $\begin{array}{l}\text { COBie, Native, PDF } \\
\text { (British Standards } \\
\text { Institution [BSI], 2013) }\end{array}$ & $\begin{array}{l}\text { IFC, native } \\
\text { (Public Procurement Service } \\
\text { [PPS], 2019) }\end{array}$ \\
\hline $\begin{array}{l}\text { Based on IFC or } \\
\text { openBIM }\end{array}$ & $\begin{array}{l}\text { The CORENET System } \\
\text { worked with IFC building } \\
\text { models in } 1998\end{array}$ & $\begin{array}{l}\text { Pilot projects started } \\
\text { to use IFC in the early } \\
2000 \text { s }\end{array}$ & $\begin{array}{l}\text { The target date for } \\
\text { public sector adoption of } \\
\text { openBIM is } 2025 \\
\text { (Ojo et al., 2015) }\end{array}$ & Under development \\
\hline $\begin{array}{l}\text { Current research } \\
\text { activity }\end{array}$ & $\begin{array}{l}\text { iGrant innovation project - } \\
\text { model checker }\end{array}$ & $\begin{array}{l}\text { Development of } \\
\text { Bygglett } 2\end{array}$ & $\begin{array}{l}\text { D-COM network was } \\
\text { formed }\end{array}$ & $\begin{array}{l}\text { National R\&D project } \\
\text { for openBIM-based } \\
\text { e-Submission system }\end{array}$ \\
\hline
\end{tabular}


building commissioner, property manager, and property developer. Statsbygg conducted several pilot projects using IFC starting in the early 2000s. BIM was mandated on all public sector projects in 2010 (Kassem et al., 2015). The Byglett project was implemented as a pilot project in 2013 to enable users to visually identify the construction project in an online environment by linking GIS information and BIM models (Kim et al., 2018b). In the autumn of 2016, a collaborative project between the ministry and the directorate was initiated to create a new version of ByggLett, termed ByggLett 2, which was completed in 2017 (Norwegian Building Authority, 2016).

\subsubsection{The United Kingdom}

In the UK, planning permits are required for new building construction or making a major modification to an existing building, such as constructing an extension or changing the building use (Gov. UK). In 2002, the UK government established a planning portal (www.planningportal. gov.uk) to provide online access to planning information, and most planning and building control applications can be submitted online to any local planning authority in the country (Planning portal, 2020). The UK BIM Programme mandated level 2 BIM (i.e., file-based collaboration and library management) on all centrally-procured government projects by 2016 (Patacas et al., 2015; Infrastructure and Projects Authority [IPA], 2016). In 2014, in collaboration with Solibri and Butler \& Young, the National Building Specification [NBS] completed a pilot project to demonstrate the tools currently available to perform automated code compliance checking using a BIM model (NBS, 2014). The Digitization of Requirements, Regulations, and Compliance Checking Processes in the Built Environment (D-COM) network was formed to advance the digitization of regulations, requirements, and compliance checking systems in the built environment (D-COM Network Portal, 2020).

\subsubsection{South Korea}

In South Korea, from 2008, the building submission has been improved by non-visit submission and real-time aggregation through the internet. From 2009, through an intelligent architecture administration system project, SEUMTER has been developed and was expanded nationwide in 2011. Currently the permission process is mainly based on checking $2 \mathrm{D}$ drawings and is expanding towards checking based on BIM (Kim et al., 2018a; SEUMTER homepage, 2020). The Public Procurement Service has mandated BIM since 2016 PPS, 2019). Since 2013 , a national research and development project funded by MOLIT has been developing an openBIM-based e-Submission system that can connect with the existing building administration system. The Korean government is working to improve the existing e-Submission system, SEUMTER, to be BIM-based e-Submission and automated code compliance checking system.

\subsection{Automated code checking technology-related research}

In recent years, automated code checking technology has received great attention in academic research. There are several classic summative papers. Eastman et al. (2009) made a survey for rule checking systems to lay out a framework for this area. Automated code checking technology has been attempted in different domains. For example, Tan et al. (2010) presented an integrated approach of applying automated code checking to building envelope design. Martins and Monteiro (2013) introduced a computer system for performing the automated code checking for water system network designs. Choi et al. (2014) developed a BIM-based evacuation code checking prototypical system. Getuli et al. (2017) applied code checking method to site safety planning for supporting the design-making, etc. Since automated code compliance checking is based on the BIM data. In order to ensure the accuracy of checking results, the quality of BIM data should be assured. There are several studies about BIM data quality assurance. For example, Lee et al. (2018) proposed a new BIM data evaluation method according to different requirements of Model View Definition (MVD). Shin et al. (2015) established an automated BIM quality pre-checking system to improve BIM design quality effectively and efficiently. Zadeh et al. (2017) presented a structured framework for information quality assessment of building information models for facility management uses. Koo and Shin (2018) did a research about applying novelty detection for identifying misclassifications for BIM elements in IFC classes, etc. Currently, development of automated code compliance checking mainly depends on manual analysis of building code and hard-coding for supporting rules. Due to the large number of regulations and the frequent updating of the regulations, the development of an automatic code checking system requires a significant amount of work (Kim et al., 2019). Several recent studies have attempted to use artificial intelligence technology to automatically extract the regulatory information necessary for automated code checking. For example, Zhang and El-Gohary (2017) proposed a new unified automated code checking system by integrating semantic language processing techniques and semantic logic reasoning. Zhou and El-Gohary (2017) proposed an ontology-based information extraction algorithm for extracting energy requirements from energy conservation codes for supporting automated energy compliance checking, etc. In addition, many scholars have made other efforts in the research of automated code compliance checking by different approaches. For example, Bloch and Sacks (2018) did a research of using machine algorithms for semantic enrichment of BIM models. Solihin et al. (2017) discussed the critical role of accessible data for analyzing BIM data and proposed a simplified schema approach called BIMRL. Dimyadi et al. (2016) described a workflow model driven approach for automating compliant design procedures. 
Preidel and Borrmann (2016) and Kim et al. (2018b) described visual language approaches. Pauwels et al. (2011) described a code checking approach in a semantic rule checking environment, etc.

\subsection{Summary}

The review for the e-Submission systems shows that several countries have established the building e-Submission platform and adopted the policy to mandate the use of BIM. For checking the submitted BIM models, these countries are actively exploring the application of code checking technology to building e-Submission system. Meanwhile, scholars have performed research on many aspects of related technologies, and several issues have been solved theoretically by researchers, such as data quality assurance issue, automatic regulatory information extracting issue, and so on. However, for actual integration of BIM into an existing building administration system, the related systemic framework and supporting software must be in place. A framework of an openBIM-based KBIM eSubmission prototypical system is proposed in this study. The framework of this prototypical system is discussed in subsequent sections.

\section{Methodology for building the framework of openBIM-based KBIM building e-Submission prototypical system}

\subsection{Traditional permitting process issues}

The traditional permitting process is divided into three main phases: design (design documents are produced), submittal (design documents are submitted), and permitting (officers check the documents).

Design phase: The designers must ensure that the design not only meets the applicable codes and regulations but also satisfies the requirements of the owners. However, because constant change is inherent to the design process, the checking required ensuring building code compliance can be a considerable effort.

Submission phase: The designers submit permit application forms and prepare the necessary information, such as $2 \mathrm{D}$ drawings and related documents, which are all information collected and input manually. This phase involves a significant data input workload and generates input errors.

Permitting phase: The officers typically check several projects at the same time to determine whether the design meets the building code and to inform the applicant of any compliance issues. The manual building code compliance checking involved in this phase consumes substantial time and resources.

The most significant challenge during the design and permitting phases is the repeated checking required to ensure conformity to the building codes. The main issue encountered in the submission phase is the efficient submittal of the design information to the permitting officers.

\subsection{BIM file features and the necessity of IFC}

$\mathrm{BIM}$ is data-rich, while CAD data is predominantly geometric. In addition to geometric information, BIM files provide relationship and attribute information (Sharma et al., 2017). Compliance with building codes could be automatically checked based on the BIM data by applying programming logic. If the data from the BIM files could be extracted automatically at the submittal stage, the workload and the number of input errors could be reduced. Because the commonly used software packages that facilitate BIM creation use different native file formats (Harty et al., 2015), it is different to require that applicants submit files in a specific software format. If there is no restriction on the data format submitted, the system should be able to check files submitted in their native formats, which would require developing different checking applications for each data format, thus creating burdens on system development and upgrades. IFC is an open international standard for the BIM data that are exchanged and shared among the software applications used by the various participants in the construction or facility management industry sector (International Organization for Standardization [ISO], 2018). The IFC data model, developed and maintained by buildingSMART International, is the key to facilitating interoperability in a cost-effective way and has been broadly supported by most BIM software companies (Eastman et al., 2011; Malsane et al., 2015). It is not dependent on specific design tools and is suitable for public works applications. Therefore, the IFC data model was selected as the BIM data format for the permission process in the proposed system.

\subsection{Proposed system modules}

Four primary operational modules were developed: code checking, submission, pre-checking, and automated rulemaking (Table 2). These will be combined with the features of BIM files to address permitting process issues.

\subsubsection{Code checking module}

Commercial code checking software based on IFC has been developed, such as FORNAX (Solihin et al., 2004).

Table 2. Summary of the primary applications constituting the four main modules

\begin{tabular}{|l|l|}
\hline \multicolumn{1}{|c|}{ Proposed modules } & \multicolumn{1}{|c|}{$\begin{array}{c}\text { Main applications for } \\
\text { implementation }\end{array}$} \\
\hline Code checking module & $\begin{array}{l}\text { KBIM Assess-Lite } \\
\text { (General user version) } \\
\text { KBIM Assess } \\
\text { (Permitting officer version) }\end{array}$ \\
\hline Submission module & KBIM Submission \\
\hline Pre-checking module & KBIM Veri \\
\hline $\begin{array}{l}\text { Automated rule-making } \\
\text { module }\end{array}$ & KBIM Logic \\
\hline
\end{tabular}


The related checking technology is mature. A code-checking module was included in the KBIM e-submission process to greatly improve efficiency. Two user groups will perform the automated code checking: general users and permitting officers, and different features and use cases are required for each. Two checking applications were developed, KBIM Assess-Lite and KBIM Assess. KBIM AssessLite is a stand-alone application for automated code compliance checking that is used in the design phase. KBIM Assess provides the same checking functionality as KBIM Assess-Lite and has been developed specifically to interface with SEUMTER, the system was used by the permitting officers.

\subsubsection{Submission module}

Various documents must be submitted as part of the building permitting process, including 2D drawings, BIM files (if needed), and other related application forms. Most of the submitted information is derived from the design and is often repeatedly provided during the application process. Meanwhile, the documents that are submitted are relatively unorganized and require a unified management approach. Therefore the submission module is the primary module in the KBIM submission system and is intended to assist applicants with their document submittals.

\subsubsection{Pre-checking module}

Because the BIM model is created artificially, there will inevitably be a variety of errors in BIM models, and they may fail to meet the BIM model guidelines or other requirements for e-submission. Therefore, it is necessary to ensure model quality before the final submission because the code compliance checking is based on the BIM data, and a pre-checking application, KBIM Veri, was developed for this purpose.

\subsubsection{Automated rule-making module}

The KBIM Assess and KBIM Assess-Lite checking applications evaluate whether submittals comply with the pertinent building codes. Building codes have many provisions and are frequently changed and expanded. KBIM Logic and KBIM Code were developed to manage and maintain the Korean building code into computational rule set files to support various KBIM applications.

\section{Prototypical openBIM-based KBIM e-Submission system}

Integrating the four main function modules discussed in Section 2.3, the entire openBIM-based KBIM e-Submission process is constituted in Figure 1. The authors will present an overview of the whole process, including the functionality of each part and their connectivity. The BIM models are delivered with the international neutral building standard data model 'IFC' throughout the permitting process.

\subsection{KBIM Collaboration}

KBIM Collaboration was developed based on openBIM as the platform for information storage and exchange among stakeholders. Collaborative design activities can be performed, and permitting-related project information, such as BIM model history, work history, RFIs, coordination, and issues, can be managed, as shown in Figure 2. Finally, this application interacts with the building permitting submission application, KBIM Submission (see Section 3.4), to deliver all necessary and suited data for producing the permitting documents (Yu et al., 2016).

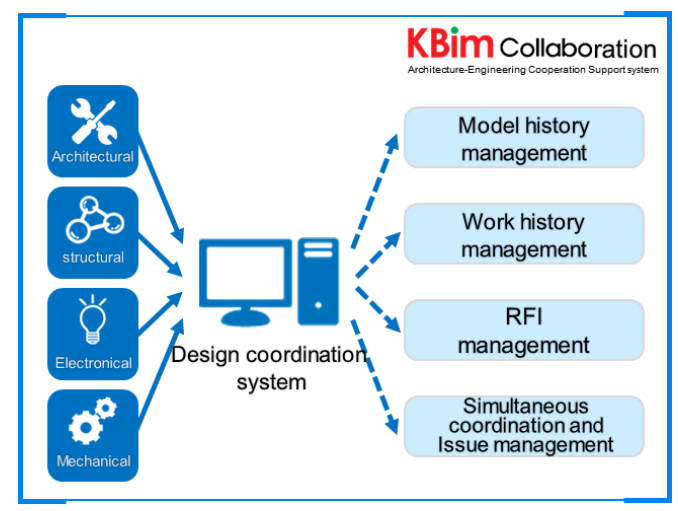

Figure 2. KBIM Collaboration (KBIMS website, 2020)

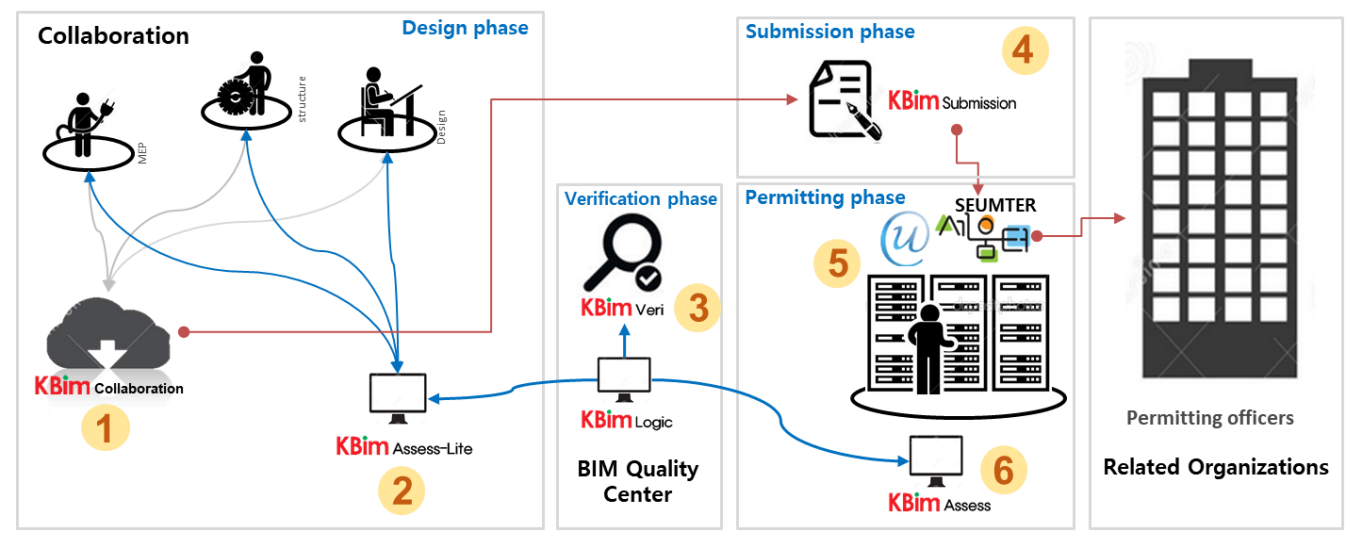

Figure 1. OpenBIM-based KBIM e-submission process (KBIMS website, 2020) 
In the process of utilizing KBIM collaboration, project participants can freely work across different BIM applications using supported international open standard formats, industry foundation classes (IFC) and BIM collaboration formats (BCF). Project management information can be extracted from IFC model, and design coordination can be communicated by using BCF (Choi \& Kim, 2017).

\subsection{Design phase}

KBIM Assess-Lite is used for automated code compliance checking, which will assist architects, BIM modelers, designers, and other stakeholders who participate in this project phase.

\subsubsection{Development of KBIM Assess-Lite}

The design process must meet the needs of the owners as well as satisfy the applicable building codes, and checking building code compliance consumes significant amounts of staff time and can introduce human error. An automatic code checking module was developed, which primarily consists of the KBIM Assess-Lite application, as shown in Figure 3.

\subsubsection{KBIM Assess-Lite functionality}

KBIM Assess-Lite is a rule-based BIM model checking application that assesses the quality of IFC-based BIM models (Figure 4). This 'Lite' version is intended to support individual users (e.g., architects) by providing a convenient tool for evaluating BIM models in the early stages of project design. Users select regulatory clauses to extract a checklist, which KBIM Assess-Lite then uses to check the model. The results of the checking can be visualized in a real-time 3D viewer and can also be exported into a Microsoft $^{\circ}$ Excel ${ }^{\circ}$ file. KBIM Assess-Lite aims to reduce errors that could cause issues in the subsequent submission and permitting phases.

\subsection{Verification phase}

Before submitting a project to SEUMTER for building permitting, the BIM models are verified for quality via the BIM Quality Center, a part of which is the KBIM Veri application.

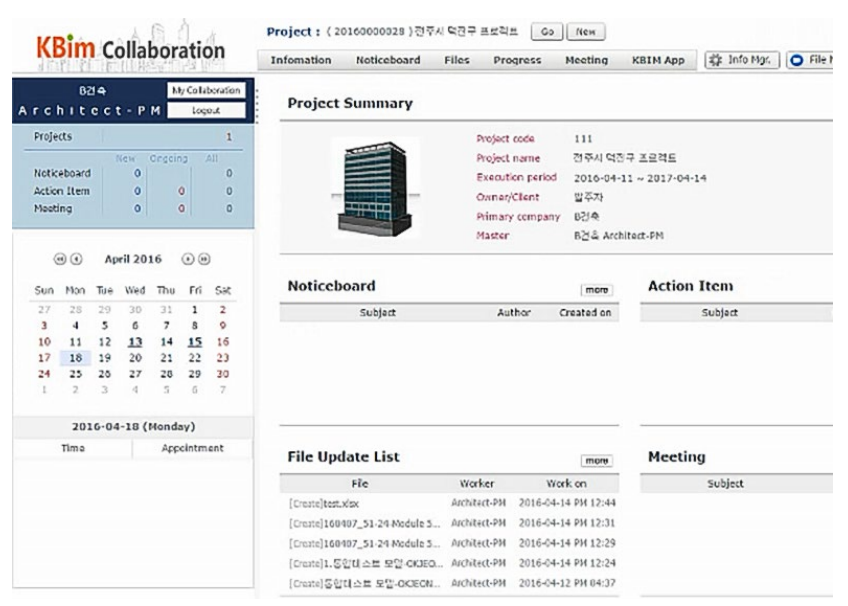

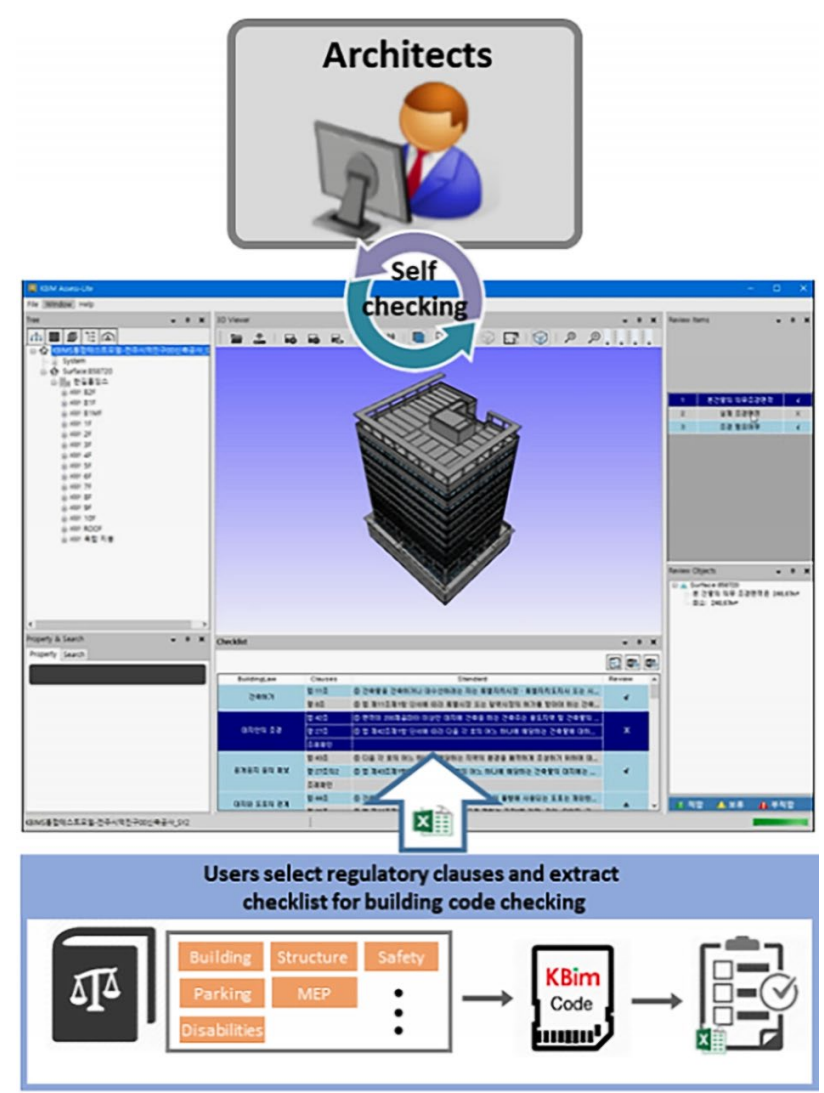

Figure 4. Automated code compliance checking using KBIM Assess-Lite (Choi \& Kim, 2017)

\subsubsection{KBIM Veri development}

Due to the fact that the BIM model is created manually, there will inevitably be errors or items that are non-compliance with modeling guidelines. In addition to meeting the modeling guidelines or requirements, the model must also provide the information required to perform the automated checking (e.g., attribute and name information). If the BIM data is not accurate, the checking result will also not be accurate. The permit approvers require a model that conforms to the automatic checking system standards to avoid expending resources identifying model

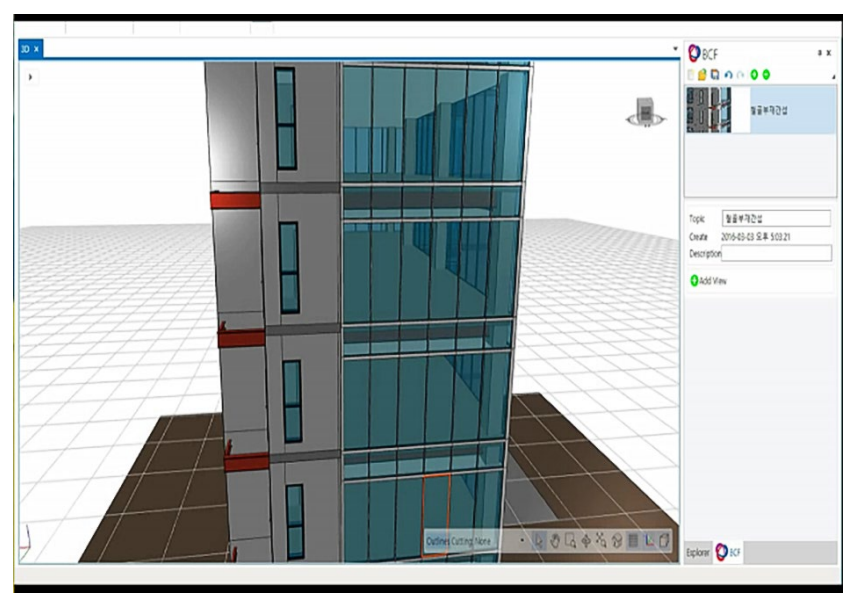

Figure 3. Design collaboration work by using KBIM collaboration 
errors. Thus, the quality of the BIM data must be checked before submittal, which is performed in the proposed system by the KBIM Veri application (Kim et al., 2019).

\subsubsection{KBIM Veri functionality}

KBIM Veri is the main application for BIM data quality checking in the quality center (Figure 5). Users submit the IFC-compliant files to the quality center and select the purpose of the submission. The KBIM Veri application then pre-checks the model to determine whether the necessary information has been included in the files. If the result is 'Pass', the system provides a verification certification from the quality center website. If the result is 'Fail', the user can get a checking report for reference, modify their model accordingly, and resubmit, until passes the pre-checking process (Kim et al., 2019).

\subsection{Submission phase}

The KBIM Submission application interfaces with SEUMTER and extracts the data necessary for building permitting directly from the BIM models uploaded to the application. This increases the submission process efficiency and decreases administrative work. Currently, the submission of 2D drawings is still required for the existing SEUMTER system (Choi \& Kim, 2017).

\subsubsection{KBIM Submission development}

Currently, designers submit permits manually online, which is time-consuming and error-prone, and subjectivity could also be an issue. These factors may lead to inef- ficiencies that increase the time required for the building permitting process (Kim \& Yu, 2014a). An essential feature of a BIM model is the data it contains, which could currently require manual input; these data could potentially be automatically extracted from the BIM data. Meanwhile, the documents submitted are varied and unorganized, thus requiring a unified management tool. Therefore, the submission module was developed, and its primary application is KBIM Submission.

\subsubsection{KBIM Submission functionality}

KBIM Submission can manage permitting information, including the building model, permitting documents, and agreement documents. KBIM Submission also functions as the building permitting information management application, which contains the same items as SEUMTER does currently. The application is interfaced with the KBIM Collaboration system to get the necessary and suited data. KBIM submission can extract the data required for building permission directly from BIM model, and fully supports openBIM. Using the IFC based BIM model, users can easily manage the process from design to submission due to the highly automated feature of KBIM submission. Out of traditional processes, 280 different categories of information (based on new builds) can now be automated (Choi \& Kim, 2017). Some permission information can be extracted from the design process from KBIM Collaboration, such as report permission, drawings, documents, etc. In addition, some data can be extracted from the BIM model, such as general information, buildings and story information, etc. as shown in Figure 6 (Yu et al., 2016).

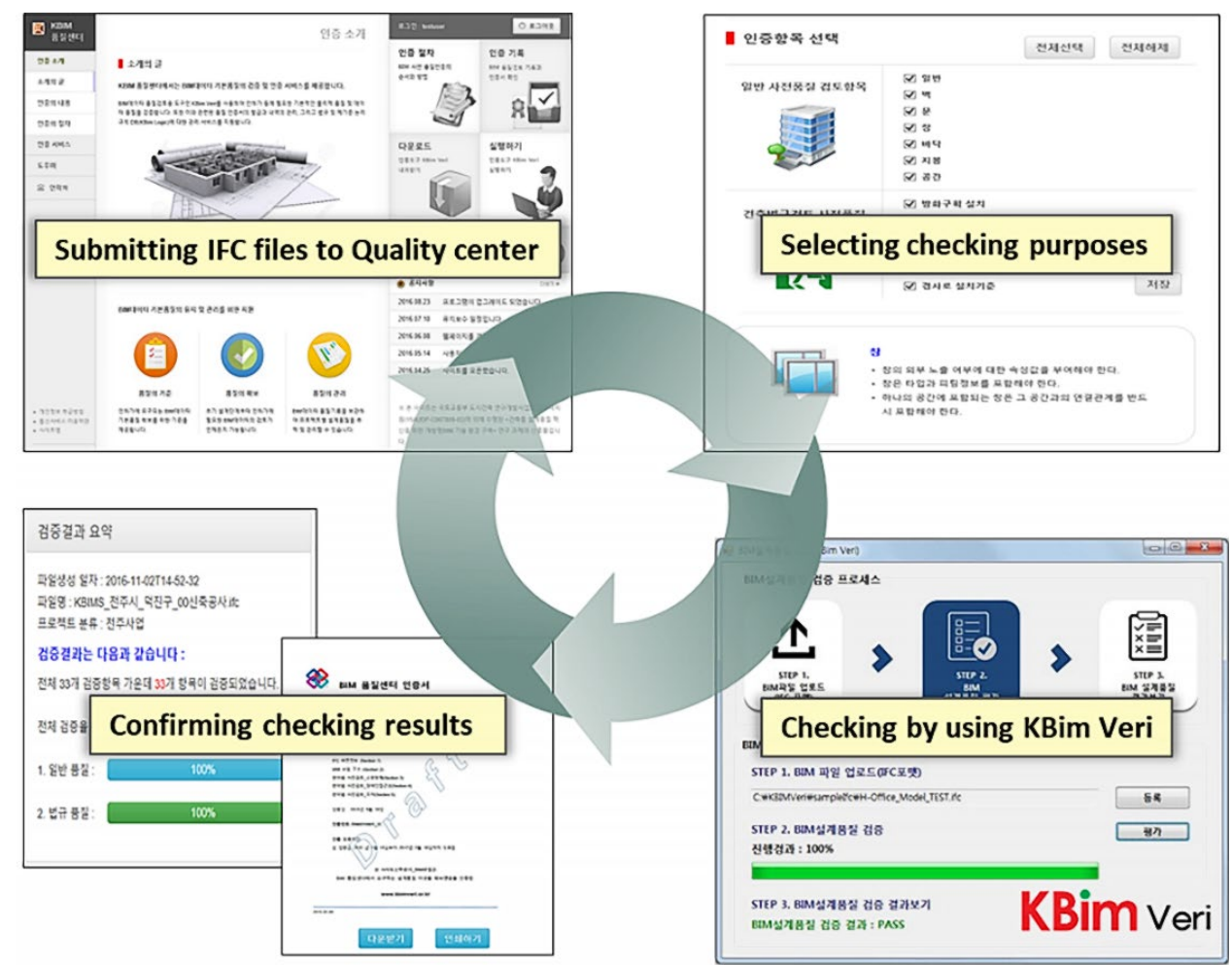

Figure 5. Pre-checking BIM data quality using KBIM Veri 


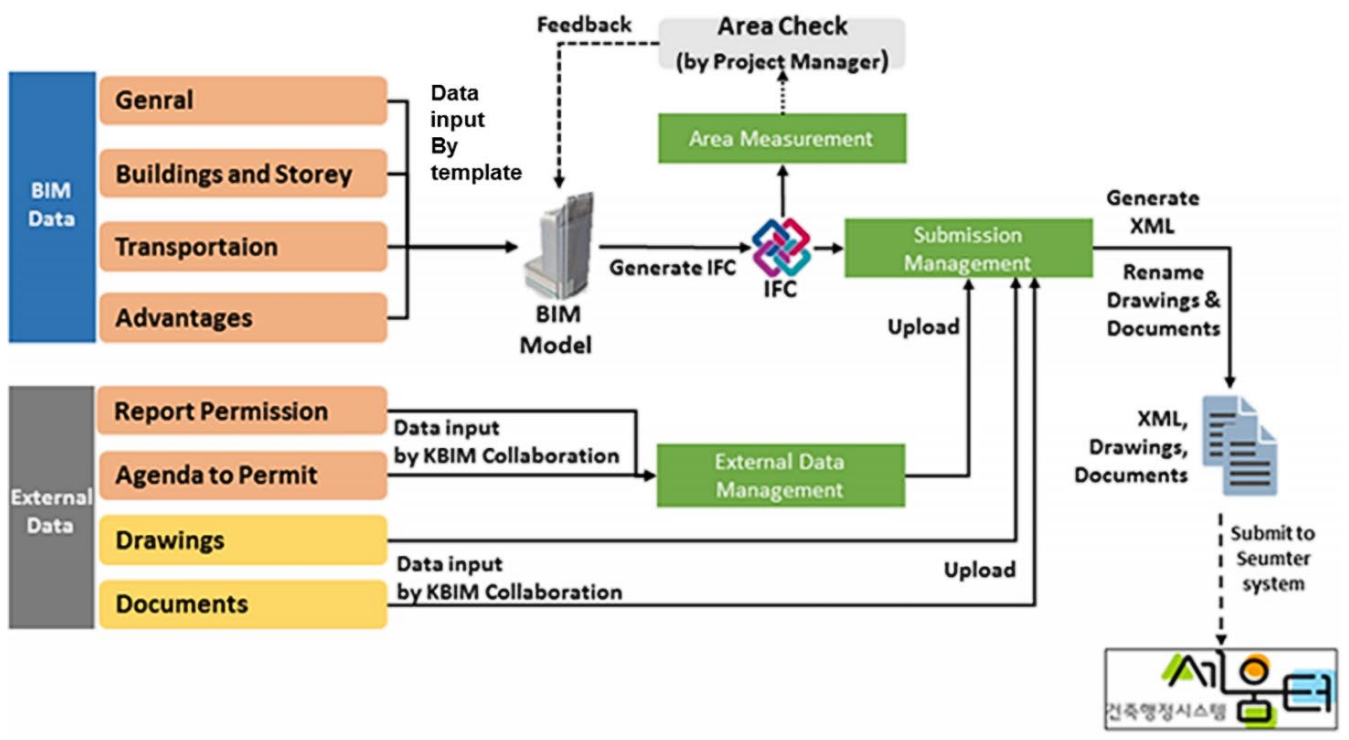

Figure 6. E-Submission by using KBIM Submission (Choi \& Kim, 2017)
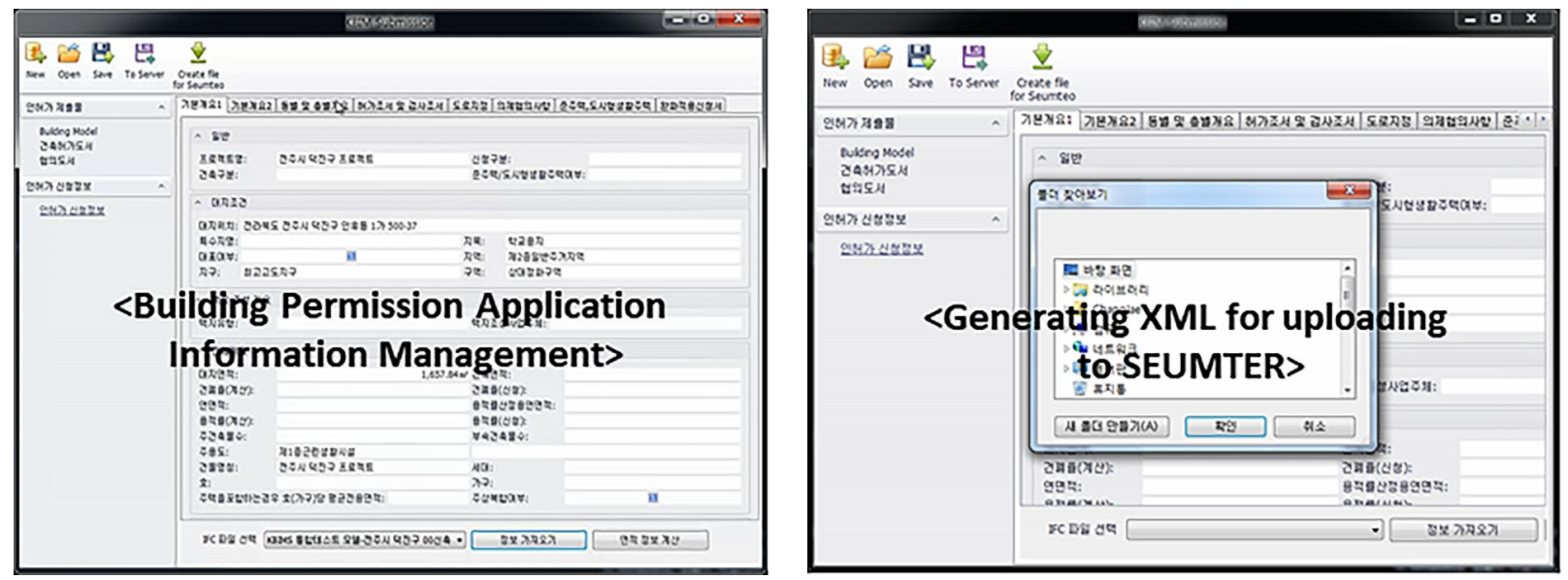

Figure 7. KBIM Submission interface

Because this information extraction is automated, it can greatly improve productivity by reducing the need for manual and repetitive input. Furthermore, the data submitted can be exported as an XML file, which can be submitted to SEUMTER (Yu et al., 2016) (Figure 7).

\subsection{Permitting phase}

In the last permitting stage, the officers check the submitted IFC files, which were previously checked by KBIM Veri. KBIM Assess is part of the e-Submission system and has the same checking functionality as KBIM Assess-Lite (Figure 8). However, unlike KBIM Assess-Lite, which can be executed as a stand-alone application for use by the public, KBIM Assess is for use only by SEUMTER authorities, and its operation relies on the SEUMTER system. It only checks models provided by the system. The checking results are delivered directly back to the SEUMTER system.

\subsection{Automated design code checking fundamentals}

The development of an automatic code checking system requires a significant amount of work for developers to translate human language into computer-recognized language due to the large number of regulations and the frequent updating of the building codes. The development of artificial intelligence technology facilitates the automatic translation of building codes that exist in natural language morphology into computer-recognizable language. KBIM Code resulted from this technology and can be used for software development through the utilization of the KBIM Logic application (Lee et al., 2016; Kim et al., 2019). The backbone of the KBIM e-Submission system is supported by KBIM Logic and KBIM Code, which are the rule-based logic and computed codes metadata upon which the automated code compliance checking is based. 


\subsubsection{KBIM Logic and KBIM Code composition}

KBIM Logic is a logical rule-based management system that can be used to convert the sentences of the rules from the Korean Building Codes (natural language) into the KBIM Code (computer-executable format) (Lee et al.,
2016; Choi \& Kim, 2017) (Figure 9). The KBIM Logic composed of a meta database derived from Korean building regulations and codes, and the logical rule-based mechanism (Lee et al., 2016).

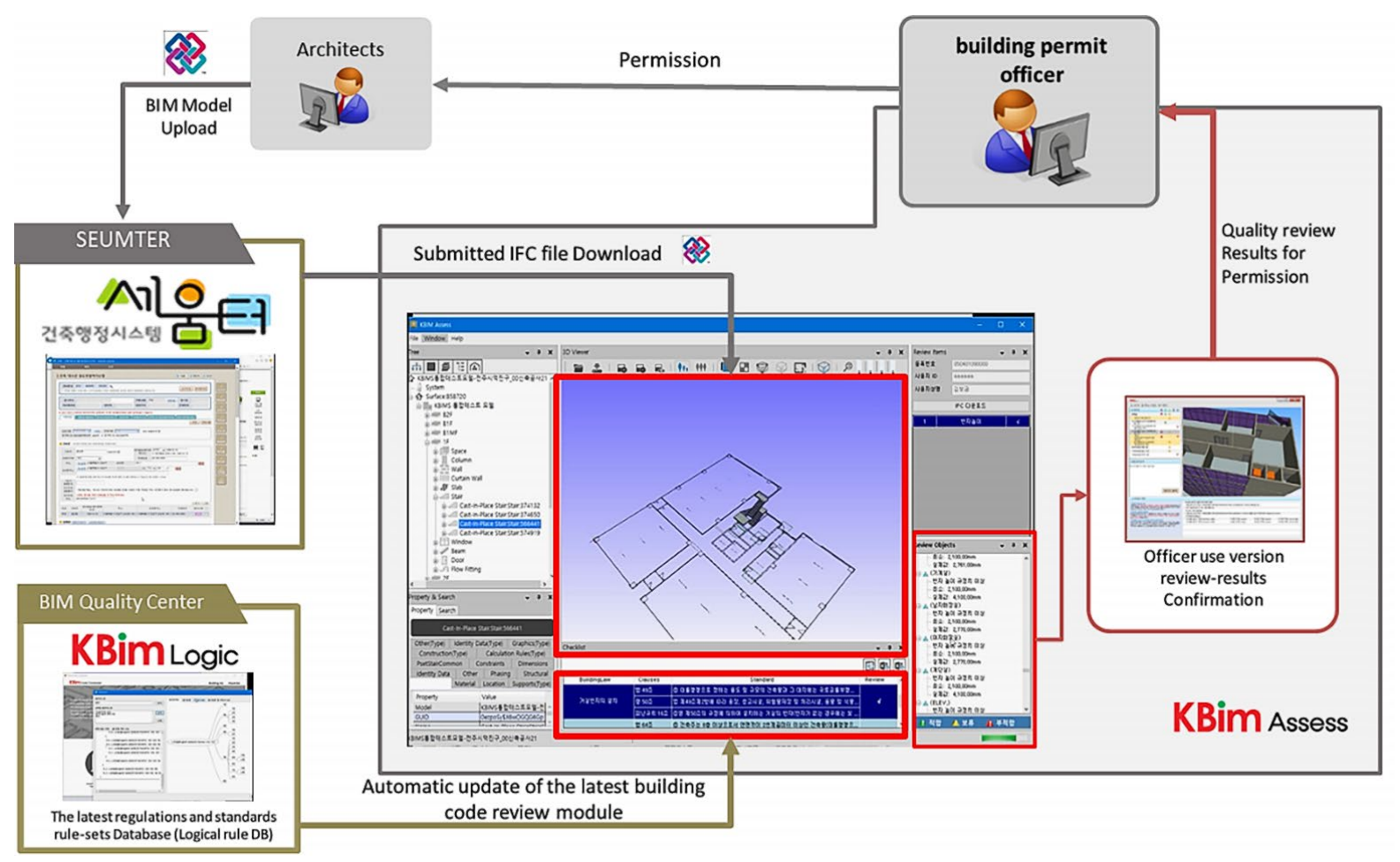

Figure 8. Permitting phase using KBIM Assess (Choi \& Kim, 2017)

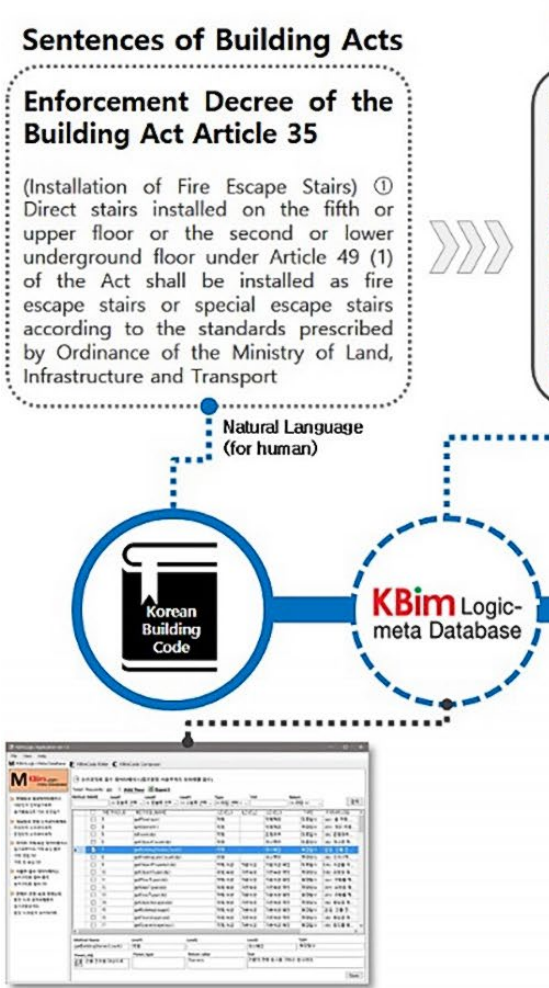

Logic-rule based mechanism based on meta database

Enforcement Decree of the Building Act Article 35

(Installation of Fire Escape Stairs) (1) Direct stairs installed on the fifth or upper floor or the second or lower underground floor under Article 49 (1) of the Act shall be installed as fire escape stairs or special escape stairs according to the standards prescribed by Ordinance of the Ministry of Land, Infrastructure and Transport

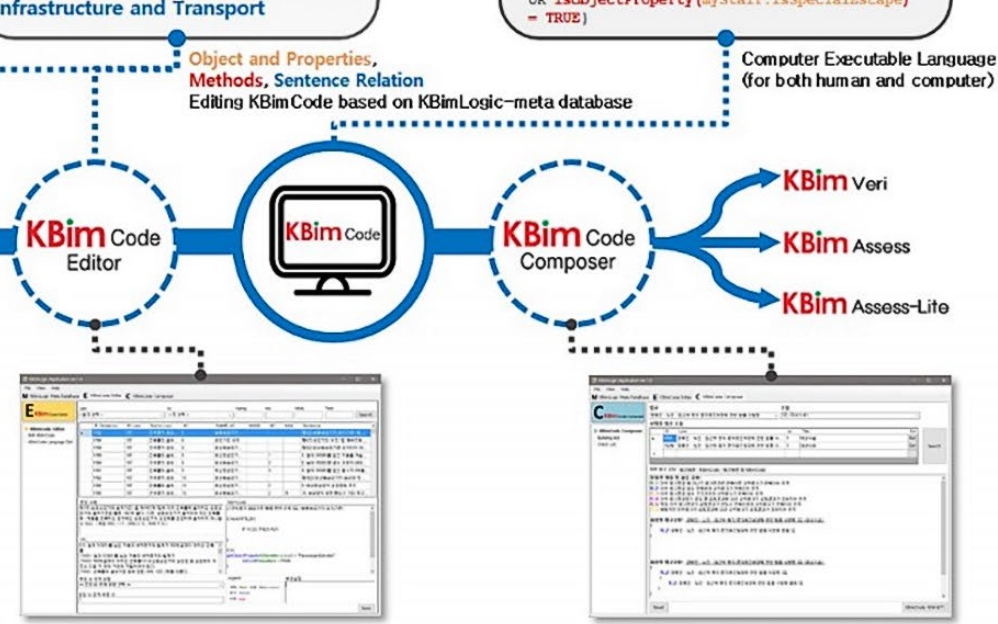

Figure 9. KBIM Logic and KBIM Code (KBIMS website, 2020) 
KBIM Code is the set of intermediate script language codes for the sentences within the Korea Building Code. KBIM Code is established as a database that can be reused and executed in accordance with the Building Code. KBIM Code is generated and managed by KBIM Logic. An exported series of KBIM Codes can be used in various BIM assessment software, such as KBIM Assess, KBIM Assess-Lite, and KBIM Veri (Choi \& Kim, 2017).

\section{KBIM prototypical building e-Submission system validation}

A virtual SEUMTER system was built to validate the effectiveness of the developed system, and it has the same environment as SEUMTER. An office building located in Jeonju City, South Korea, was selected for the validation. The building has two underground floors, ten aboveground floors, and a total floor area of $14179.54 \mathrm{~m}^{2}$. The entire permitting process was performed using the prototypical KBIM e-Submission system, as shown in Figure 10.

\section{Results and discussion}

The authors tested the feasibility of the proposed prototypical KBIM building e-Submission system, received positive users' feedback, and obtained significant results.

1. Since the submission was based on the IFC file format, which is an international standard data model, designers did not need to use specific BIM software. Meanwhile, using the automated code checking system greatly liberated the labor force of designers and officers.
2. In the previous design process, each participant works separately and there is no effective unified platform to manage documents, project data, and personnel information. KBIM Collaboration significantly improved the collaboration and efficiency of the participants.

3. Currently, the manual input of permitting information takes one person an average of 3-4 days and results in inconsistencies (Kim \& Yu, 2014b). Using KBIM Submission, the required information could be automatically extracted from KBIM Collaboration and the IFC files, and an XML file could then be generated for the final submittal. The process greatly reduced the input time and increased the accuracy of the information.

4. The entire permitting process currently requires an average of one month (i.e., the general permitting period plus the permitting reservation period). As a significant part of the permitting process could be automated, the permitting period could be shortened significantly.

\section{Conclusions and future works}

In order to improve Korean existing e-Submission system, SEUMTER, to provide for BIM-based e-Submission and automated code compliance checking e-Submission system; Korean government funded the Korea BIM (KBIM) building e-Submission system project. In this study, the intellectual contributions to improve the existing e-Submission system were made and the system proposed.

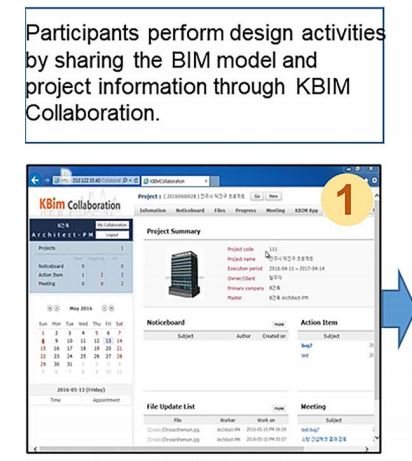

KBIM Collaboration

KBIM Assess

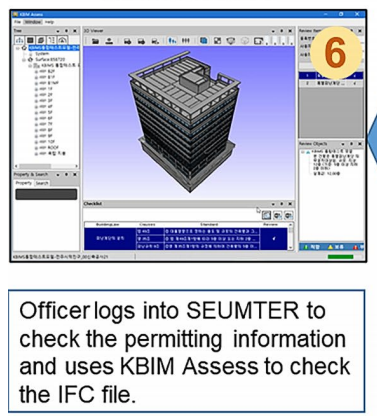

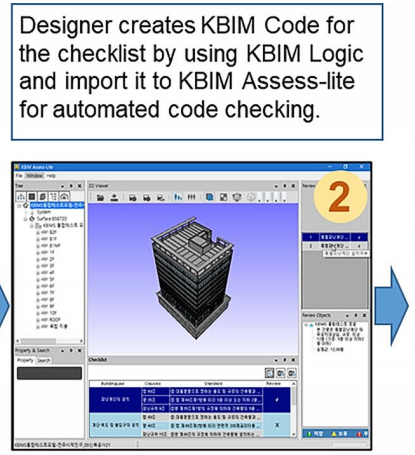

KBIM Assess-Lite

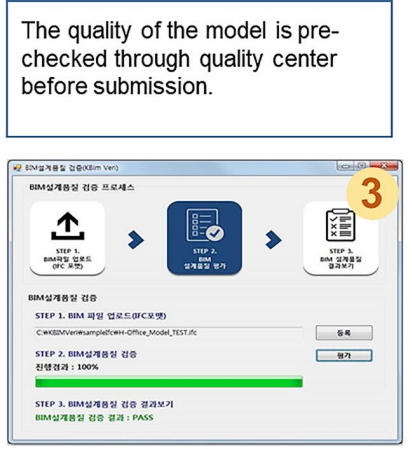

Quality center

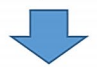

KBIM Submission

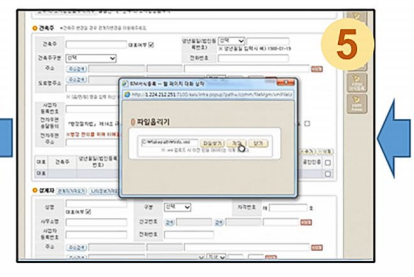

Applicant uploads the XML file generated in KBIM Submission and submit the IFC file to SEUMTER
Applicant creates building submission application information through KBIM Submission application

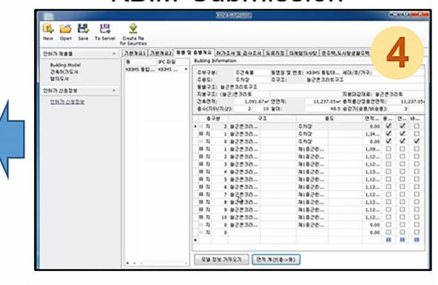

Figure 10. Prototypical KBIM building e-Submission system process 
This proposed a framework for an openBIM-based KBIM e-Submission prototypical system to support government initiatives to promote the use of BIM technology and improve the existing $2 \mathrm{D}$ based building permitting process. This proposed system has an integrated and creative innovation which comprises a series of functional modules. These modules are incorporated in combination with the existing working mode of each stage which are interrelated. The proposed modules constitute an organic framework for e-submission. The international neutral building standard data model 'IFC' was used as the information carrier throughout the permitting process. The system was successfully validated in an actual project, and the feasibility of the framework was verified.

The authors hope that through the application of the openBIM-based KBIM e-Submission prototypical system proposed in this research will help to actively guide the use of BIM technology from the government level. South Korea's efforts for developing this proposed system could also provide a good reference for other countries. Meanwhile, the standard building data obtained through this system will provide an important data basis for the future digital management of the government and digital fusion with other related field and also for the application of artificial intelligence in construction industry.

The following technical issues were addressed in this study when developing the proposed framework:

1. An openBIM-based collaboration platform was developed to provide a design collaboration environment based on openBIM. In addition, it can also ensure that the information needed for the permission is retained in the design process. Combined with KBIM submission, it can avoid duplicate input for permission application.

2. Two types of automated code compliance checking modules were developed for self-checking by designers and permitting checking by officers.

3. A pre-checking module was developed to ensure the quality of the BIM model and improve the accuracy of the code checking results.

4. A rule-making module was developed to create KBIM code for driving various KBIM applications, such as KBIM Assess-Lite and KBIM Assess.

However, the system is still in the verification stage, so it needs to be augmented and improved to be practically applicable:

1. Only a portion of the building code checking items was developed for the concept validation in this study. Therefore, many building code items require further development.

2. Some special cases will still require manual prechecking of the BIM model quality, due to uncontrollable factors that occur during the modeling process. Artificial intelligence technology will be introduced to improve the accuracy of the pre-checking.

3. During the design process, not only could the building code compliance be checked automatically, but the building performance could also be evaluated automatically. The authors will continue to explore automated building performance evaluation based on IFC models.

4. At present, the proposed framework has only been applied to a virtual environment of the existing building permitting system to verify its feasibility. The existing permitting system architecture requires further upgrades to improve the efficiency of the building permitting process.

\section{Acknowledgements}

This research was supported by a grant (20AUDPB127891-04) from the Architecture \& Urban Development Research Program funded by the Ministry of Land, Infrastructure and Transport of the Korean government.

\section{Funding}

This research was supported by a grant (20AUDPB127891-04) from the Architecture \& Urban Development Research Program funded by the Ministry of Land, Infrastructure and Transport of the Korean government.

\section{Author contributions}

I. H. Kim was responsible for the project administration, paper conceptualization, funding acquisition, paper review, J. C. Choi was responsible for the paper methodology and paper review, E. A. L. Teo was responsible for the paper review, H. W. Sun was responsible for the research analysis and paper writing.

\section{Disclosure statement}

The authors declare that they have no known competing financial interests or personal relationships that could have appeared to influence the work described in this paper.

\section{References}

Bloch, T., \& Sacks, R. (2018). Comparing machine learning and rule-based inferencing for semantic enrichment of BIM models. Automation in Construction, 91, 256-272.

https://doi.org/10.1016/j.autcon.2018.03.018

British Standards Institution. (2013). BSI 2013 PAS 1192-2:2013: Specification for information management for the capital/delivery phase of construction projects using building information modelling. London, UK.

Building and Construction Authority. (2015). Deadlines for projects requiring mandatory BIM e-Submission for regulatory approval. https://www.corenet.gov.sg/media/1170470/ appbca-2015-07-circular-on-deadlines-for-mandatory-bime-submission.pdf

Building and Construction Authority. (2016a). Code of practice for Building Information Modelling (BIM) e-Submission. https://www.corenet.gov.sg/media/2157490/1_cp_for_bim_ esubmission_gr_v1-1.pdf

Building and Construction Authority. (2016b). 2-Stage Innovation Grant (iGrant) call for proposals for solutions on automat- 
ed code compliance check in BIM. https://www.corenet.gov.sg/ media/2032978/igrant-circular-code-compliance-check-forbim-.pdf

Cheng, J. C. P., \& Lu, Q. (2015). A review of the efforts and roles of the public sector for BIM adoption worldwide. ITcon, 20, 442-478.

Choi, J., \& Kim, I. (2015). Development of an Open BIM-based Legality System for building administration permission services. Journal of Asian Architecture and Building Engineering, 14, 577-584. https://doi.org/10.3130/jaabe.14.577

Choi, J., \& Kim, I. (2017). A methodology of building code checking system for building permission based on openBIM. In Proceedings of the 34th ISARC (pp. 945-950), Taipei, Taiwan. https://doi.org/10.22260/ISARC2017/0131

Choi, J., Choi, J., \& Kim, I. (2014). Development of BIM-based evacuation regulation checking system for high-rise and complex buildings. Automation in Construction, 46, 38-49. https://doi.org/10.1016/j.autcon.2013.12.005

Choi, J., Lee, Y., \& Kim, I. (2018). Development of application for generation of automatic 2D drawings based on openBIM. In Proceedings of the 35th ISARC (pp. 356-361), Berlin, Germany. https://doi.org/10.22260/ISARC2018/0050

D-COM Network portal. (2020). https://www.dcom.org.uk/ about-d-com/

Dimyadi, J., Clifton, C., Spearpoint, M., \& Amor, R. (2016). Computerizing regulatory knowledge for building engineering design. Journal of Computing in Civil Engineering, 30(5). https://doi.org/10.1061/(ASCE)CP.1943-5487.0000572

Eastman, C., Lee, J., Jeong, Y., \& Lee, J. (2009). Automatic rulebased checking of building designs. Automation in Construction, 18, 1011-1033.

https://doi.org/10.1016/j.autcon.2009.07.002

Eastman, C., Teicholz, P., Sacks R., \& Liston, K. (2011). BIM handbook: a guide to building information modeling for owners, managers, designers, engineers and contractors (2nd ed.). Wiley.

Edirisinghe, R., \& London, K. (2015). Comparative analysis of international and national level BIM standardization efforts and BIM adoption. In Proceedings of the 32nd International Conference of CIB W78 (pp. 149-158), Eindhoven, The Netherlands.

GeBIZ. (2020). Tender No. BCA000ETT20300006. https://www. gebiz.gov.sg/

Getuli, V., Ventura, S., Capone, P., \& Ciribini, A. (2017). BIMbased code checking for construction health and safety. Procedia Engineering, 196, 454-461.

https://doi.org/10.1016/j.proeng.2017.07.224

Harty, J., Kouider, T., \& Paterson, G. (2015). A guide for small and medium-sized architecture, engineering and construction firms (1st ed.). Routledge. https://doi.org/10.4324/9781315730721

Hjelseth, E. (2015). Public BIM-based model checking solutions: lessons learned from Singapore and Norway. Building Information Modelling (BIM) in Design, Construction and Operations, 149, 421-436. https://doi.org/10.2495/BIM150351

Infrastructure and Projects Authority. (2016). Government construction strategy 2016-2020. https://assets.publishing. service.gov.uk/government/uploads/system/uploads/attachment_data/file/510354/Government_Construction_Strategy_2016-20.pdf

International Organization for Standardization. (2018). ISO 16739-1:2018 Industry foundation classes for data sharing in the construction and facility management industries - Part 1 : Data schema. https://www.iso.org/standard/70303.html
Kassem, M., Succar, B., \& Dawood, N. (2015). Building Information Modeling: Analyzing noteworthy publications of eight countries using a knowledge content taxonomy. In R. Issa \& S. Olbina (Eds.), Building information modeling: Applications and practices in the AEC industry (pp. 329-371). ASCE Press. https://doi.org/10.1061/9780784413982.ch13

Kim, H., Lee, J., Shin, J., \& Choi, J. (2018a). Visual language approach to representing KBimCode-based Korea Building code sentences for automated rule checking. Journal of Computational Design and Engineering, 6(2), 143-148. https://doi.org/10.1016/j.jcde.2018.08.002

Kim, I., Jang, J., \& Choi, J. (2018b). A study on the additional properties management method for building code automated checking by BIM. Korean Journal of Computational Design and Engineering, 23(2), 92-104.

https://doi.org/10.7315/CDE.2018.092

Kim, I., Hwang, K., \& Sun, H. (2019). The role of BIM data quality checking in the process of BIM based e-Submission. In i3CDE 2019 Proceedings, Penang, Malaysia.

Kim, K., \& Yu, J. (2014a). Improvement of BIM-based building approval system. In Proceedings of the International Conference on Advances in Civil, Structural and Mechanical Engineering (CSME 2014) (pp. 17-21), Hong Kong.

Kim, K., \& Yu, J. (2014b). Improvement of BIM-based building permit process. In Proceedings of the KCICI Academic Conference 2014, Seoul, South Korea.

Koo, B., \& Shin, B. (2018). Applying novelty detection to identify model element to IFC class misclassifications on architectural and infrastructure Building Information Models. Journal of Computational Design and Engineering, 5(4), 391-400.

https://doi.org/10.1016/j.jcde.2018.03.002

KBIMS website. (2020). KyungHee University Consortium. http://dq.kbims.or.kr/

Lee, H., Lee J., Park S., \& Kim, I. (2016). Translating building legislation into a computer executable format for evaluating building permit requirements. Automation in Construction, 71(1), 49-61. https://doi.org/10.1016/j.autcon.2016.04.008

Lee, Y., Eastman, C., \& Solihin, W. (2018). Logic for ensuring the data exchange integrity of building information models. Automation in Construction, 85, 249-262. https://doi.org/10.1016/j.autcon.2017.08.010

Malsane, S. M., Matthews, J., Lockley, S., Love, P. E., \& Greenwood, D. (2015). Development of an object model for automated compliance checking. Automation in Construction, 49, 51-58. https://doi.org/10.1016/j.autcon.2014.10.004

Martins, J., \& Monteiro, A. (2013). LicA: A BIM based automated code-checking application for water distribution systems. Automation in Construction, 29, 12-23.

https://doi.org/10.1016/j.autcon.2012.08.008

National Building Specification. (2014, February18). NBS pioneering automated checking of building regulations. https:// www.thenbs.com/about-nbs/press-releases/nbs-pioneeringautomated-checking-of-building-regulations

Norwegian Building Authority. (2016). Annual report: Good building for a good society. https://www.regjeringen.no/contentassets/bef58a2b56824de4bedb0d7c0e5d42da/2016_arsrapport.pdf

Ojo, A. O., Rahimian, F. P., Goulding, J., \& Pye, C. (2015). Construction education requirements for achieving level 2 and 3 BIM. In ARCOM Doctoral Workshop on Construction Education in the New Digital Age (pp. 34-48), Birmingham City University, UK. 
Preidel, C., \& Borrmann, A. (2016). Towards code compliance checking on the basis of a visual programming language. Itcon, 21 (Special issue CIB W78 2015 Special track on Compliance Checking), 402-421.

Patacas, J., Dawood, N., Vukovic, V., \& Kassem, M. (2015). BIM for facilities management: evaluating BIM standards in asset register creation and service life. ITcon, 20, 313-331.

Pauwels, P., Deursen, D. V., Verstraeten, R., Roo, J. D., Meyer, R. D., Walle, R. V., \& Campenhout, J. M. (2011). A semantic rule checking environment for building performance checking. Automation in Construction, 20(5), 506-518. https://doi.org/10.1016/j.autcon.2010.11.017

Planning portal. (2020). https://www.planningportal.co.uk/

Public Procurement Service. (2019). Facility business BIM basic guidelines.

SEUMTER homepage. (2020). Version of SEUMTER. https://www.eais.go.kr

Sharma, S., Sawhney, A., \& Arif, M. (2017). Parametric modelling for designing offsite construction. Procedia Engineering, 196, 1114-1121. https://doi.org/10.1016/j.proeng.2017.08.069

Shin, J., Choi, J., \& Kim, I. (2015, October 11-14). A study on the development of BIM-based quality pre-checking system in architecture design phase. In Proceedings of the 6th International Conference on Construction Engineering and Project Management (ICCEPM 2015), Busan, Korea.

Solihin, W., Shaikh, N., Rong, X., \& Poh, L. K. (2004). Beyond interoperability of building models: A case for code compliance checking [Conference presentation]. BP-CAD Workshop, Carnegie Melon University.

Solihin, W., Dimyadi, J., Lee, Y., Eastman, C., \& Amor, R. (2017, July 4-7). The critical role of accessible data for BIM-based automated rule checking systems. In Proceedings of the Joint Conference on Computing in Construction (JC3). Lean and Computing in Construction Congress (LC3) (pp. 53-60). Heraklion, Greece.

Statsbygg. (2013). Statsbygg building information modelling manual. Version1.2.1 (SBM1.2.1).

Tan, X., Hammad, A., \& Fazio, P. (2010). Automated code compliance checking for building envelope design. Journal of Computing in Civil Engineering, 24(2), 203-211. https://doi.org/10.1061/40937(261)32

Yu, J., Park, M., Lee, J., \& Yeo, C. (2016). Introduction to the OpenBIM-based Design Cooperation (KBIM Collaboration) and the permission application support system (KBIM Submission). Korea Journal of Construction Engineering and Management, 17(4), 41-46.

Zadeh, P., Wang, G., Cavka, H., Staub-French, S., \& Pottinger, R. (2017). Information quality assessment for facility management. Advanced Engineering Informatics, 33, 181-205. https://doi.org/10.1016/j.aei.2017.06.003

Zhang, J., \& El-Gohary, N. (2017). Integrating semantic NLP and logic reasoning into a unified system for fully-automated code checking. Automation in Construction, 73, 45-57. https://doi.org/10.1016/j.autcon.2016.08.027

Zhou, P., \& El-Gohary, N. (2017). Ontology-based automated information extraction from building energy conservation codes. Automation in Construction, 74, 103-117.

https://doi.org/10.1016/j.autcon.2016.09.004 